\title{
SCIDOC
}

\author{
International Journal of Dentistry and Oral Science (IJDOS) \\ ISSN: $2377-8075$
}

\section{Prevalence Of Periodontitis Among Different Age Groups: A Retrospective Study}

\section{Research Article}

\author{
Keerthika.S ${ }^{1}$, Arvina Rajasekar ${ }^{2}$, Santhosh $\operatorname{Kumar}^{3}$
}

${ }^{1}$ Saveetha Dental College and Hospitals, Saveetha Institute of Medical and Technical Sciences, Chennai - 600 077, TN, India.

${ }^{2}$ Department of Periodontics, Saveetha Institute of Medical and Technical Sciences, Saveetha University, 162, Chennai - 600077, Tamil Nadu, India.

${ }^{3}$ Department of Oral and Maxillofacial Surgery, Saveetha Dental College and Hospitals, Saveetha Institute of Medical and Technical Sciences (SIMATS) Saveetha University, Chennai, India.

\section{Abstract}

Periodontitis is a highly prevalent oral disease that ranges from gingival inflammation to loss of teeth and supporting structures. It affects a wide range of people across all age groups and genders. It is the major cause of loss of teeth among all other oral diseases affecting the people. This study aims to evaluate the prevalence of periodontitis among different age groups. This retrospective study was done by analysing the case records of periodontitis patients. A total of 640 periodontitis patients were randomly recruited. Data regarding the patient's periodontal status were collected from the case records and analysed. Descriptive statistics and inferential statistics were done using SPSS Software, Version 23. Among 640 periodontitis patients, 536 patients had generalised periodontitis $(83.75 \%)$ and 104 patients had localised periodontitis $(16.25 \%)$. The prevalence of generalised periodontitis was higher among the age group of 36-45 year old patients (25.7\%) and localised periodontitis was most prevalent among 26-35 year old patients $(5.6 \%)$. The association between age and the type of periodontitis was statistically not significant. In gender wise assessment, generalised periodontitis was prevalent among 323 males $(50.4 \%)$ and 213 females (33.2\%). localised periodontitis was prevalent among 62 males $(9.6 \%)$ and 42 females $(6.5 \%)$. Both localised and generalised periodontitis show a male predominance.

Keywords: Bacterial Plaque; Gingivitis; Periodontitis; Inflammation.

\section{Introduction}

Periodontitis, a chronic infectious disease, affects most of the population at one time or the other and its expression is a combination of hosts, microbial agents, and environmental factors [1]. It does not appear to be a single disease with variations in clinical symptoms, but a group of diseases with overlapping symptomatology [2]. Etiology is however complex with many factors at risk, of which, few are biological such as age, systemic conditions, and others are behavioral factors such as smoking and oral cleanliness $[2,3]$.

Periodontal disease is a group of lesions affecting the tissues surrounding and supporting teeth [5]. Majority of diseases of periodontium can be classified as either gingivitis or periodontitis or periodontitis as a manifestation of systemic disease [6]. The primary etiology of periodontal disease is bacterial plaque. However the disease is modified by a variety of risk factors like age, gender, stress, malnutrition, smoking, systemic disease, genetic factors [7].

Age is one of the risk determinants of periodontal disease [8]. Aging is a complex multifactorial process that increases susceptibility to chronic inflammatory diseases and microbial infections, such as periodontitis. Older individuals have higher levels of some Gram-negative bacilli, such as Pseudomonas aeruginosa, Klebsiella pneumonia, and Enterobacter, as compared with young individuals [4]. However, relatively little is known on how aging affects oral bacterial communities [5]. Also differences in demographic characteristics and levels of exposure to various risk factors among different populations can partially explain the wide range in the prevalence of periodontal disease, but their variance can also be a result of differences in periodontal examination protocol $[4,6]$. Epidemiological studies on prevalence of periodontitis helps in implementation and planning of oral health programs.

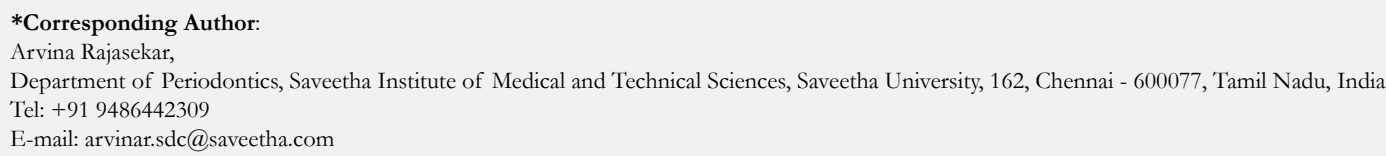

Copyright: Arvina Rajasekar ${ }^{\circ}$ 2021. This is an open-access article distributed under the terms of the Creative Commons Attribution License, which permits unrestricted use, distribution and reproduction in any medium, provided the original author and source are credited. 
Previously our team has a rich experience in working on various research projects across multiple disciplines [7-21]. This study aims to assess the prevalence of periodontitis among different age groups.

\section{Materials And Methods}

This retrospective study was conducted among periodontitis patients above 18 years who visited a private dental college in chennai from June 2019 to March 2020. Prior permission to utilise the data for the analysis was obtained from the Institution Ethics Board with the ethical approval number being: SDC/ SIHEC/2020/DIASDATA/0619-0320. Study participants were divided based on the age as follows: $18-25$ years, $26-35$ years, 3645 years, $46-55$ years $56-65$ years and $66-75$ years.

A total of 640 periodontitis patients above 18 years were randomly recruited. Consecutive sampling method was carried out. Cross verification of data was done via photographs, data evaluation was done with two reviewers and cross verified with third reviewer. Relevant data such as age and gender were recorded. Patients with systemic illness, those with a habit of smoking and those who were on long term medications were excluded from the study. Repeated and incomplete data records were excluded. Data was verified by an external reviewer. Data regarding the periodontal status of the patients were collected from the case records and analysed.

Data was retrieved and entered in Microsoft Excel sheet and later exported to SPSS software (Version 23.0) for statistical analysis. Descriptive (frequency distribution and percentage) and inferential statistics (chi-square test) were done using SPSS software. Level of significance was set as $\mathrm{p}<0.05$ for this study.

\section{Results And Discussion}

In the present study, among 640 periodontitis patients, $536 \mathrm{pa}-$ tients had generalised periodontitis (83.75\%) and 104 patients had localised periodontitis $(16.25 \%)$ [Figure 1].

The study participants were divided based on the age as follows: 18-25 years, 26-35 years, 36-45 years, 46-55 years, 56-65 years and 66-75 years. The prevalence of generalised periodontitis was higher among the age group of 36-45 year old patients $(25.7 \%)$ followed by $26-35$ year old patients $(23.4 \%$ ), followed by $46-55$ year old patients $(16.5 \%)$, followed by $18-25$ year old patients $(8.1 \%)$, followed by $56-65$ year old patients $(7.6 \%)$ and $65-75$ year old patients $(2.1 \%)$.

The prevalence of localised periodontitis was higher among the age group of 26-35 year old patients (5.6\%) followed by 36-45 year old patients $(4.2 \%)$, followed by $46-55$ year old patients $(3.1 \%)$, followed by $18-25$ year old patients $(1.8 \%)$, followed by $56-65$ year old patients $(0.78 \%)$ and $65-75$ year old patients $(0.63 \%)$. The association between age and periodontitis was analysed using chisquare test and was found to be statistically not significant with the $\mathrm{p}$ value of 0.452 [Figure 2].

Out of 640 periodontitis patients, there were 385 males and 255 females. The type of periodontitis was assessed based on the gender. Generalised periodontitis was prevalent among 323 males (50.4\%) and 213 females $(33.2 \%)$. Localised periodontitis was prevalent among 62 males $(9.6 \%)$ and 42 females (6.5\%). Both generalised and localised periodontitis show a male predominance. The association between gender and the periodontitis was analysed using chi-square test and was found to be statistically insignificant with the $\mathrm{p}$ value of 0.493 [Figure 3].

In the current study participants were classified into age groups 18-25 years, 26- 35 years, 36-45 years, 46-55 years, 56- 65 years, 6675 years. This is in accordance with study by Akbar and partiwi et al, reported age can be classified into seven groups namely early adolescence (12-16 years), late adolescence (17-25 years), young adults (26-35 years), late Adults (36-45 years), early elderly (46-55 years), late elderly (56-65 years) and senior $>65$ years. Prevalent age groups with periodontitis were found to be between 26-45 years [22]. This is contradictory to finding that prevalence and severity of periodontal disease tends to increase with patient age [23-25]. Another contradictory findings showed that chronic periodontitis occurred frequently in all age groups with an increasing percentage in the older age $(56 \%),(74 \%)$ in adults and $(80 \%)$ in elderly [26]. Bokhari et al reported that subjects aged 40 years and above were four times more likely to have periodontitis [27].

Increased prevalence in aging attributed that with aging, oral epithelial cells have reduced mitotic activity and metabolic rate [28]. General deterioration in immune functions and tissue integrity in the older age group serve as a hypothesis for the weakness of periodontal disease. In the current study no significant correlation with prevalence of periodontitis with age group was observed. Contradictory to findings by Bhadbhade et al shows significant correlation between periodontal disease and age group [29]. Cur-

Figure 1: Bar graph depicting the distribution of type of periodontitis among the study population. $\mathrm{X}$ axis represents type of periodontitis and $\mathrm{Y}$ axis represents the number of patients. The more prevalent periodontal disease is generalized periodontitis (Green) which constitutes to $83.75 \%$ when compared to localized periodontitis (Orange) which constitutes to $16.25 \%$.

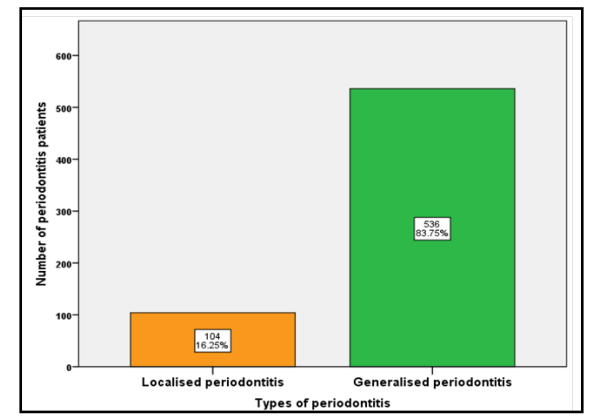


Figure 2: This bar graph shows association between different age groups and periodontitis. $\mathbf{X}$ axis represents age groups and $Y$ axis represents the number of periodontitis patients. Generalised periodontitis (Green) was prevalent among the 3645 year old patients $(25.78 \%)$ and Localized periodontitis was most prevalent among the $26-35$ year old patients $(5.63 \%)$. The association between different age groups and periodontitis was statistically not significant (Chi-square analysis, $\mathrm{p}=0.452)$.

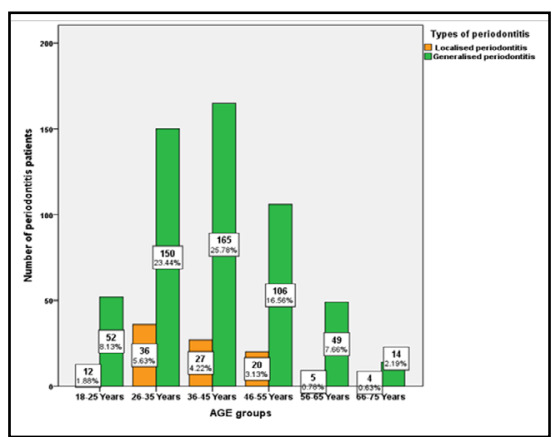

Figure 3: This bar graph shows association between gender and periodontitis. $\mathrm{X}$ axis represents gender and $\mathrm{Y}$ axis represents the number of periodontitis patients. Both generalised $(50.47 \%)$ and localised $(9.69 \%)$ periodontitis showed a male predominance. The association between gender and periodontitis was statistically not significant (Chi-square analysis, $\mathrm{p}=0.493)$.

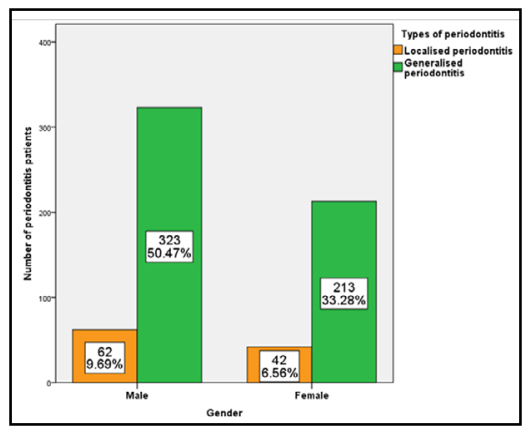

rent knowledge has shown that periodontitis does not present a linear progression and is not age dependent. Moreover, its distribution and severity are strongly influenced by host susceptibility and risk factors. Several epidemiological studies evaluating destructive periodontal diseases have been pursuing associations in the incessant identification of risk factors for these diseases. Analytical epidemiology seeks to identify the risk factors associated with a disease, to quantify the strength of those associations and to estimate whether an association is causal [30]. An understanding of risk factors can lead to theories of causation and then to treatment protocols for clinicians to use in their daily practice.

In the present study, periodontitis was prevalent among males when compared to females. This is in accordance with studies done by Doifode et al, Kundu et al, and Sekhon et al which have concluded that periodontal disease was more common in males, with the explanation put forward being the deleterious oral habits which are more prevalent in male population [25].Our institution is passionate about high quality evidence based research and has excelled in various fields [26-36].

The limitations of the present study includes limited sample size and similar ethnicity. Therefore, multicenter studies need to be conducted among larger populations to confirm this finding. Within the limitations, the present study showed that generalised periodontitis $(25.78 \%)$ was more prevalent in the age group of $36-45$ years and localised periodontitis $(5.63 \%)$.

\section{Conclusion}

Within the limits of the study, it can be observed that generalised periodontitis $(25.78 \%$ ) was more prevalent in the age group of 36-45 years and localised periodontitis (5.63\%). Both generalised and localised periodontitis showed a male predilection.

\section{Acknowledgement}

The authors of this study would like to express their gratitude towards everyone who facilitated and enabled us to carry out this study successfully. We would also thank the institute for helping us to have access to all the case records for collecting the required cases for conducting this study.

\section{References}

[1]. Slots J, Gibbons RJ. Attachment of Bacteroides melaninogenicus subsp. asaccharolyticus to oral surfaces and its possible role in colonization of the mouth and of periodontal pockets. Infect Immun. 1978 Jan;19(1):254-64. Pubmed PMID: 24002.

[2]. TRACY S. THE IMPORTANCE OF THOROUGH DENTISTRY AND OF DISINFECTION OF THE MOUTH FROM THE VIEWPOINT OF THE ABDOMINAL SURGEON. South. Med. J. 1909 Nov;2(11):1115-7.

[3]. Sheiham A, Hobdell MH, Cowell CR. Patterns of tooth loss in British populations. Studies on industrial populations. Brit. Dent. J.. 1969;126(6):25560 .

[4]. Zhang J, Xuan D, Fan W, Zhang X, Dibart S, De Vizio W, et al. Severity and prevalence of plaque-induced gingivitis in the Chinese population. Compend Contin Educ Dent. 2010 Oct;31(8):624-9.Pubmed PMID: 20960992.

[5]. Ravi S, Malaiappan S, Varghese S, Jayakumar ND, Prakasam G. Additive Effect of Plasma Rich in Growth Factors With Guided Tissue Regeneration in Treatment of Intrabony Defects in Patients With Chronic Periodontitis: A Split-Mouth Randomized Controlled Clinical Trial. J Periodontol. 2017 Sep;88(9):839-845.Pubmed PMID: 28474968.

[6]. Chandra A, Yadav OP, Narula S, Dutta A. Epidemiology of periodontal diseases in Indian population since last decade. J Int Soc Prev Community 
Dent. 2016 Mar-Apr;6(2):91-6.Pubmed PMID: 27114945.

[7]. Hafeez N. Accessory foramen in the middle cranial fossa. Res J Pharm Technol. 2016;9(11):1880-2.

[8]. Krishnan RP, Ramani P, Sherlin HJ, Sukumaran G, Ramasubramanian A, Jayaraj G, et al. Surgical Specimen Handover from Operation Theater to Laboratory: A Survey. Ann Maxillofac Surg. 2018 Jul-Dec;8(2):234-238. Pubmed PMID: 30693238.

[9]. Somasundaram S, Ravi K, Rajapandian K, Gurunathan D. Fluoride Content of Bottled Drinking Water in Chennai, Tamilnadu. J Clin Diagn Res. 2015 Oct;9(10):ZC32-4.Pubmed PMID: 26557612

[10]. Felicita AS. Orthodontic extrusion of Ellis Class VIII fracture of maxillary lateral incisor - The sling shot method. Saudi Dent J. 2018 Jul;30(3):265269.Pubmed PMID: 29942113.

[11]. Kumar S, Rahman R. Knowledge, awareness, and practices regarding biomedical waste management among undergraduate dental students. Asian J Pharm Clin Res. 2017;10(8):341.

[12]. Gurunathan D, Shanmugaavel AK. Dental neglect among children in Chennai. J Indian Soc Pedod Prev Dent. 2016 Oct 1;34(4):364.

[13]. Sneha S. Knowledge and awareness regarding antibiotic prophylaxis for infective endocarditis among undergraduate dental students. Asian J. Pharm. Clin. Res. 2016 Oct 1:154-9.

[14]. Dhinesh B, Lalvani JI, Parthasarathy M, Annamalai K. An assessment on performance, emission and combustion characteristics of single cylinder diesel engine powered by Cymbopogon flexuosus biofuel. Energy Convers. Manag. 2016 Jun 1;117:466-74.

[15]. Choudhari S, Thenmozhi MS. Occurrence and Importance of Posterior Condylar Foramen. Res J Pharm Technol. 2016;9(8):11-43.

[16]. Paramasivam A, Vijayashree Priyadharsini J, Raghunandhakumar S. N6adenosine methylation (m6A): a promising new molecular target in hypertension and cardiovascular diseases. Hypertens Res. 2020 Feb;43(2):153154.Pubmed PMID: 31578458.

[17]. Wu F, Zhu J, Li G, Wang J, Veeraraghavan VP, Krishna Mohan S, et al. Biologically synthesized green gold nanoparticles from Siberian ginseng induce growth-inhibitory effect on melanoma cells (B16). Artif Cells Nanomed Biotechnol. 2019 Dec;47(1):3297-3305.Pubmed PMID: 31379212.

[18]. Palati S, Ramani P, Shrelin HJ, Sukumaran G, Ramasubramanian A, Don $\mathrm{KR}$, et al. Knowledge, Attitude and practice survey on the perspective of oral lesions and dental health in geriatric patients residing in old age homes. Indian J Dent Res. 2020 Jan-Feb;31(1):22-25.Pubmed PMID: 32246676.

[19]. Saravanan M, Arokiyaraj S, Lakshmi T, Pugazhendhi A. Synthesis of silver nanoparticles from Phenerochaete chrysosporium (MTCC-787) and their antibacterial activity against human pathogenic bacteria. Microb Pathog. 2018 Apr;117:68-72.Pubmed PMID: 29427709.

[20]. Govindaraju L, Gurunathan D. Effectiveness of Chewable Tooth Brush in Children-A Prospective Clinical Study. J Clin Diagn Res. 2017 Mar;11(3):ZC31-ZC34.Pubmed PMID: 28511505.

[21]. Vijayakumar Jain S, Muthusekhar MR, Baig MF, Senthilnathan P, Loganathan S, Abdul Wahab PU, et al. Evaluation of Three-Dimensional Changes in Pharyngeal Airway Following Isolated Lefort One Osteotomy for the Correction of Vertical Maxillary Excess: A Prospective Study. J Maxillofac Oral Surg. 2019 Mar;18(1):139-146.Pubmed PMID: 30728705.

[22]. Ramesh A, Varghese SS, Jayakumar ND, Malaiappan S. Chronic obstructive pulmonary disease and periodontitis-unwinding their linking mechanisms. J Oral Biosci. 2016 Feb 1;58(1):23-6.
[23]. Kavarthapu A, Thamaraiselvan M. Assessing the variation in course and position of inferior alveolar nerve among south Indian population: A cone beam computed tomographic study. Indian J Dent Res. 2018 JulAug;29(4):405-409.Pubmed PMID: 30127186.

[24]. Khawaja AR, Bokhari SM, Tariq R, Atif S, Muhammad H, Faisal Q, et al. Disease Severity, Quality of Life, and Psychiatric Morbidity in Patients With Psoriasis With Reference to Sociodemographic, Lifestyle, and Clinical Variables: A Prospective, Cross-Sectional Study From Lahore, Pakistan. Prim Care Companion CNS Disord. 2015 Jun 25;17(3):10.4088/PCC.14m01629. Pubmed PMID: 26644955.

[25]. Sekhon TS, Grewal S, Gambhir RS. Periodontal health status and treatment needs of the rural population of India: A cross-sectional study. J. Nat. Sci. Biol. Med. 2015 Jan;6(1):111-5.

[26]. Vijayashree Priyadharsini J. In silico validation of the non-antibiotic drugs acetaminophen and ibuprofen as antibacterial agents against red complex pathogens. J Periodontol. 2019 Dec;90(12):1441-1448.Pubmed PMID: 31257588.

[27]. Pc J, Marimuthu T, Devadoss P, Kumar SM. Prevalence and measurement of anterior loop of the mandibular canal using CBCT: A cross sectional study. Clin Implant Dent Relat Res. 2018 Apr 6;20(4):531-4.

[28]. Ramesh A, Varghese S, Jayakumar ND, Malaiappan S. Comparative estimation of sulfiredoxin levels between chronic periodontitis and healthy patients - A case-control study. J Periodontol. 2018 Oct;89(10):1241-1248.Pubmed PMID: 30044495.

[29]. Ramadurai N, Gurunathan D, Samuel AV, Subramanian E, Rodrigues SJ. Effectiveness of $2 \%$ Articaine as an anesthetic agent in children: randomized controlled trial. Clin Oral Investig. 2019 Sep;23(9):3543-50.

[30]. Sridharan G, Ramani P, Patankar S, Vijayaraghavan R. Evaluation of salivary metabolomics in oral leukoplakia and oral squamous cell carcinoma. J Oral Pathol Med. 2019 Apr;48(4):299-306.

[31]. Ezhilarasan D, Apoorva VS, Ashok Vardhan N. Syzygium cumini extract induced reactive oxygen species-mediated apoptosis in human oral squamous carcinoma cells. J Oral Pathol Med. 2019 Feb;48(2):115-121.Pubmed PMID: 30451321.

[32]. Mathew MG, Samuel SR, Soni AJ, Roopa KB. Evaluation of adhesion of Streptococcus mutans, plaque accumulation on zirconia and stainless steel crowns, and surrounding gingival inflammation in primary molars: randomized controlled trial. Clin Oral Investig. 2020 Sep;24(9):1-6.Pubmed PMID: 31955271.

[33]. Samuel SR. Can 5-year-olds sensibly self-report the impact of developmental enamel defects on their quality of life? Int J Paediatr Dent. 2021 Mar;31(2):285-286.Pubmed PMID: 32416620.

[34]. R H, Ramani P, Ramanathan A, R JM, S G, Ramasubramanian A, et al. CYP2 C9 polymorphism among patients with oral squamous cell carcinoma and its role in altering the metabolism of benzo[a]pyrene. Oral Surg Oral Med Oral Pathol Oral Radiol. 2020 Sep;130(3):306-312.Pubmed PMID: 32773350 .

[35]. Chandrasekar R, Chandrasekhar S, Sundari KKS, Ravi P. Development and validation of a formula for objective assessment of cervical vertebral bone age. Prog Orthod. 2020 Oct 12;21(1):38.Pubmed PMID: 33043408.

[36]. Vijayashree Priyadharsini J, Smiline Girija AS, Paramasivam A. In silico analysis of virulence genes in an emerging dental pathogen A. baumannii and related species. Arch Oral Biol. 2018 Oct;94:93-98.Pubmed PMID: 30015217. 